\title{
Sacral Hiatus: An Anatomical Study
}

\author{
Dr. Irungbam Deven Singh ${ }^{1}$, Dr. L. Birendro Singh ${ }^{2}$, Dr. A. Jaishree Devi ${ }^{3}$ \\ ${ }^{1}$ Associate Professor, Department Of Anatomy, Regional Institute Of Medical Sciences, Imphal, Manipur, India \\ ${ }^{2}$ Assistant Professor, Department Of Orthopaedics, Jawaharlal Nehru Institute Of Medical Sciences, Imphal, \\ Manipur, India \\ ${ }^{3}$ Professor, Department Of Anatomy, Regional Institute Of Medical Sciences, Imphal, Manipur, India
}

\begin{abstract}
Sacrum is a triangular bone formed by the fusion of five vertebrae. The sacral hiatus is the deficiency in the lower part of the dorsal wall of the sacral canal resulting from the failure of the fusion of most commonly the laminae of the $5^{\text {th }}$ sacral vertebra. During caudal epidural anaethesia, the anaesthetic drug is injected through the sacral hiatus to gain access to the epidural space of the sacral canal. The study is an attempt to examine the morphological as well as morphometrical aspects of sacral hiatus. Thirty sacra were taken up for the study. The sacra were studied for shape of sacral hiatus, position of the apex, position of the base, width of the base, length of hiatus and its depth at the apex. The various types found in the study were inverted $U$, inverted V, Irregular, Dumb-bell and M. The inverted U type had the highest incidence (36.67\%). The location of the apex had the highest incidence at S4 (56.67\%). The base of the sacral hiatus was located most commonly located at S5 (83.33\%). The length of the sacral hiatus was mostly found to be in the range of 11-20mm (36.67\%) with an average of $18.97 \mathrm{~mm}$. The width of the base was most commonly found to be $11-15 \mathrm{~mm}$ (46.67\%) with an average of $9.13 \mathrm{~mm}$. The depth of the sacral hiatus at the level of the apex was most commonly found to be 4-6mm (70\%) with an average of $4.67 \mathrm{~mm}$. An ideal sacral hiatus would be the one which is sufficiently long, wide as well as deep. A sacral hiatus which is too long is not favorable for caudal epidural anaesthesia as it may lead to puncture of the dural sac.
\end{abstract}

Keywords. Sacrum, sacral hiatus, sacral canal, caudal epidural anaesthesia.

\section{Introduction}

Sacrum is a triangular bone of the pelvis formed by the fusion of five vertebrae. It forms the posterosuperior wall of pelvis and articulates laterally with the two hip bones, superiorly with the $5^{\text {th }}$ lumbar vertebra and inferiorly with the coccyx. The cavity of the sacrum is known as the sacral canal which forms the terminal part of the vertebral canal and houses the lower spinal nerves and filum terminale. The sacral hiatus is the deficiency in the lower part of the dorsal wall of the sacral canal resulting from the failure of the fusion of most commonly the laminae of the $5^{\text {th }}$ sacral vertebra. ${ }^{1}$ The $5^{\text {th }}$ sacral nerves, coccygeal nerves and filum terminale emerge through the sacral hiatus. The sacral cornua, which represent the inferior articular processes of the $5^{\text {th }}$ sacral vertebra, project downwards. The base of the sacral hiatus is formed by the gap between the tips of the two cornua. The intercornual ligaments bind the sacral cornua and to the coccygeal cornua. These ligaments may be ossified sometimes which may bring about a change in the shape and size of the sacral hiatus. There may be variation in the degree of fusion of laminae of the sacral vertebrae among individuals. This causes variation in the size of the sacral hiatus which determines the outcome of the clinical procedures performed in this area. During caudal epidural anaethesia the anaesthetic drug is injected through the sacral hiatus to gain access to the epidural space of the sacral canal. This is done to block the lower spinal nerves especially during delivery. But the variations in the shape and size of the sacral hiatus results in difficulty in such procedures in the people with unfavourable shape or size. The study is an attempt to examine the morphological as well as morphometrical aspects of sacral hiatus and also to highlight the issues surrounding it.

\section{Materials and Methods}

Thirty sacra were taken up for the study. The sacra were studied for 1) shape of hiatus 2) position of the apex of hiatus 3) position of the base of hiatus (position of the tips of the sacral cornua) 4) width of the base (measured between the tips of the sacral cornua) or lower ends of the ossified intercornual ligaments 5) length of hiatus (measured from the apex to the midpoint of the base of the hiatus) and 6) depth of the sacral hiatus at the apex. When the cornua were not at the same level or the intercornual ligament was ossified unilaterally, the width of the base was measured by taking the distance between the tip of the sacral cornu of the normal side to a point at the same level on the opposite side. The measurements were done with a steel Vernier caliper, divider and steel scale.

\section{Results}

The incidences of the various types were inverted U (Fig. 1), inverted V (Fig. 2), Irregular (Fig. 3), Dumb-bell (Fig. 4) and M (Fig. 5) are given in Table I. The inverted U type had the highest incidence (36.67\%). 
The inverted $\mathrm{U}$ and the inverted $\mathrm{V}$ made up to $70 \%$ of the cases. The lowest incidence was found with the $\mathrm{M}$ type $(3.33 \%)$. The location of the apex is presented in Table II with highest incidence at S4 (56.67\%) and lowest incidence at S1 and S2 (3.33\% each). The base of the sacral hiatus was located most commonly at S5 (83.33\%) and least commonly at S4 (6.67\%) (Table III). The height of the apex of the sacral hiatus as indicated by the length of the sacral hiatus was mostly found to be in the range of $11-20 \mathrm{~mm}(36.67 \%)$ with an average of $18.97 \mathrm{~mm}$ (Table IV). The width of the base was most commonly found to be $11-15 \mathrm{~mm}(46.67 \%)$ with an average of $9.13 \mathrm{~mm}$ (Table V). The depth of the sacral hiatus at the level of the apex was most commonly found to be $4-6 \mathrm{~mm}(70 \%)$ with an average of $4.67 \mathrm{~mm}$ (Table VI). Bilateral ossification of the intercornual ligament was found in $10 \%$ and unilateral ossification in $3.33 \%$ of the cases.

Table I. Types of sacral hiatus

\begin{tabular}{|c|c|c|c|c|c|}
\hline Type & Inverted U & Inverted V & Irregular & Dumb-bell & M type \\
\hline Number & 11 & 10 & 6 & 2 & 1 \\
\hline Percentage & 36.67 & 33.33 & 20 & 6.67 & 3.33 \\
\hline
\end{tabular}

Table II. Location of the apex of sacral hiatus

\begin{tabular}{|c|c|c|c|c|c|}
\hline Level & S1 vertebra & S2 vertebra & S3 vertebra & S4 vertebra & S5 vertebra \\
\hline Number & 1 & 1 & 7 & 17 & 4 \\
\hline Percentage & 3.33 & 3.33 & 23.33 & 56.67 & 13.33 \\
\hline
\end{tabular}

Table III. Location of the base of sacral hiatus

\begin{tabular}{|c|c|c|c|}
\hline Location & S4 vertebra & S5 vertebra & First Coccyx \\
\hline Number & 2 & 25 & 3 \\
\hline Percentage & 6.67 & 83.33 & 10 \\
\hline
\end{tabular}

Table IV. Length of sacral hiatus

\begin{tabular}{|c|c|c|c|c|c|}
\hline Length $(\mathrm{mm})$ & $0-11$ & $11-20$ & $21-30$ & $31-40$ & $>40$ \\
\hline Number & 7 & 11 & 7 & 4 & 1 \\
\hline Percentage & 23.33 & 36.67 & 23.33 & 13.33 & 3.33 \\
\hline
\end{tabular}

Table V. Width of sacral hiatus at the base

\begin{tabular}{|c|c|c|c|c|}
\hline Width $(\mathrm{mm})$ & $0-5$ & $6-10$ & $11-15$ & $>15$ \\
\hline Number & 7 & 8 & 14 & 1 \\
\hline Percentage & 23.33 & 26.67 & 46.67 & 3.33 \\
\hline
\end{tabular}

Table VI. Depth of sacral hiatus at the apex

\begin{tabular}{|c|c|c|c|c|}
\hline Depth $(\mathrm{mm})$ & $0-3$ & $4-6$ & $7-9$ & $>9$ \\
\hline Number & 6 & 21 & 3 & 0 \\
\hline Percentage & 20 & 70 & 10 & 0 \\
\hline
\end{tabular}

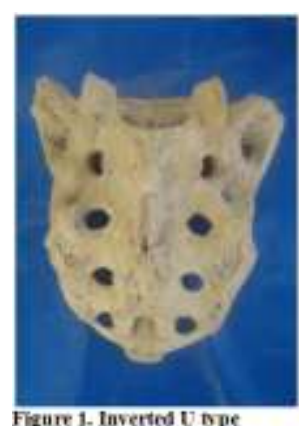

Fiqure 1. Inverted v tope

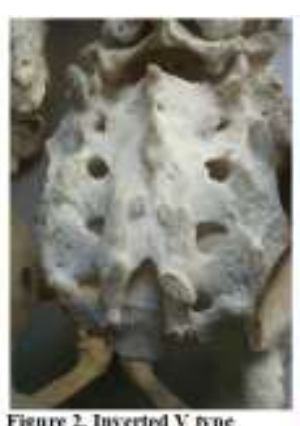

Figure 2. Inverted V 5pe

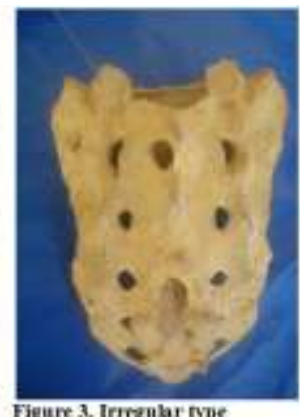

Figure 3, Irregular type
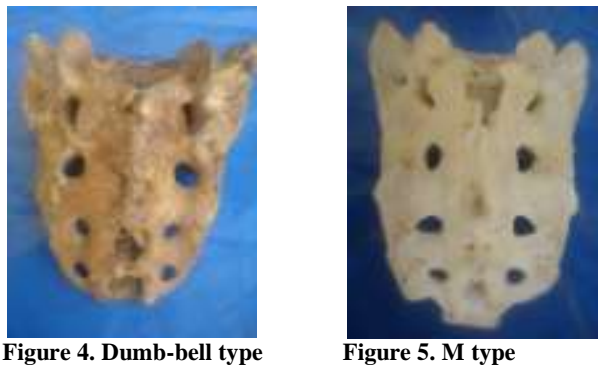


\section{Discussion}

The most common shape of the sacral hiatus is inverted $\mathrm{U}$ or inverted $\mathrm{V}$ as reported by Kumar et al ${ }^{2}$ $\left(29.70 \%, 46.53 \%\right.$ respectively), $\operatorname{Nagar}^{3}\left(41.50 \%, 27 \%\right.$ respectively), Patel et $\mathrm{al}^{4}(49.33 \%, 20 \%$ respectively), Shewale et $\mathrm{al}^{5}(40.69 \%, 32.00 \%$ respectively). The corresponding figures in the present study were $36.67 \%$ and $33.33 \%$ respectively. Most of the studies report more of inverted $\mathrm{U}$ type $\mathrm{e}^{3,4,5}$ though the inverted $\mathrm{V}$ type may be found to be the more common type ${ }^{2}$. The reason for such a disparity in the incidences of the two commonest types may be due to 1) the actual variation in the population studied and 2) the sample size. But the authors of the present study found that differentiation between the two types was sometimes difficult so that one type could be assigned to the other. This may be true for other types also. Moreover, it is suggested that the distinction between inverted $\mathrm{U}$ and $\mathrm{V}$ types is not reasonable as shown by the similarity of their pooled values. ${ }^{6}$

'Dumb-bell' is the type in which there is a constriction between the apex and the base. ${ }^{2,3,4,5,6}$ This type should be reserved for the one in which there are projections from both sides which are more or less at the same level. When there is unilateral projection, it could be termed 'irregular'. It was found that the lateral boundaries of the sacral hiatus were not completely smooth or uniform. There were cases in which tubercles on each side of the sacral hiatus were found to project medially reducing the transverse diameter of the hiatus at that level. The irregular type was so named when the hiatus could not be assigned to any of the defined types. The laminae may fail to fuse above a fused part. This type is termed 'aperture in the dorsal wall ${ }^{, 5}$ or 'bifid ${ }^{3,7,8,9}$. In the present study, the authors found sacra with deficiencies above a sacral hiatus, but these were not given a separate class. A "long" type ${ }^{4,5,7}$ has been described but it is not clear how much length of the canal should qualify it to be this type. There has been report of an ' $\mathrm{M}$ ' type $\mathrm{P}^{7}$ in which there is a downward projection in the midline indenting the apex of the sacral hiatus. Another type is the complete absence of the dorsal wall of sacral canal which has been described as 'complete spina bifida'., ${ }^{2,4,5}$ For this case, there is no apex (though the base is still present). There was no case of complete spina bifida in the present study. In a rare occurrence, there may not be sacral hiatus at all (all laminae fuse) and has been termed 'absent' type., ${ }^{2,3,4,7}$ There was no such type in the present study.

The position of the apex of sacral hiatus tells us about the length of the sacral hiatus. In the present study, the length of the sacral hiatus was most commonly found to be $11-20 \mathrm{~mm}(36.67 \%)$ which is similar to those of Seema et $\mathrm{al}^{10}$ and Vasuki et $\mathrm{al}^{11}$. In the present case, the base of sacral hiatus was found most commonly at the level of S5 vertebra $(83.33 \%)$. Seema et $\mathrm{al}^{10}$ also found the base most commonly at the same level but with a lower incidence $(70.46 \%)$. The base may be sometimes brought down to the level of the $1^{\text {st }}$ coccygeal piece when there is bilateral ossification of intercornual ligament. This was found in the present study in 3 cases (10\%). The width of the base was most commonly found to be $11-15 \mathrm{~mm}(46.67 \%)$ which is slightly less than that of Shewale et $\mathrm{al}^{5}$. The depth of the sacral hiatus at the apex was most commonly found to be 4$6 \mathrm{~mm}(70 \%)$ which is supported by the findings of Arora et al ${ }^{12}$. An ideal sacral hiatus for caudal epidural anaesthesia would be the one which is sufficiently long, wide as well as deep. But a sacral hiatus which is too long is not be favorable for caudal epidural anaesthesia as it may lead to puncture of the dural sac. ${ }^{13}$

\section{References}

[1]. Standring S. The back in Anatomy : The Anatomical Basis of Clinical Practice. 40 ${ }^{\text {th }}$ edition (Edinburgh : Elsevier, 2008), $707-48$.

[2]. Kumar V, Nayak SR, Potu BK. Sacral hiatus in relation to low backache in South Indian population. Bratisk. Lek. Listv. 110(7), 2009, 436-41.

[3]. Nagar SK. A study of sacral hiatus in dry human sacra. Journal of Anatomical Society of India, 53 (2), 2004, 18-21.

[4]. Patel ZK, Thummar B, Rathod SP, Single TC, Patel S, Zalawadia A. Multicentric morphometric study of dry human sacrum of Indian population in Gujarat region. NJIRM, 2(2), 2011, 31-35.

[5]. Shewale SN, Laeeque M, Kulkarni PR, Diwan CV. Morphological and morphometrical study of sacral hiatus. International Journal of Recent Trends in Science and Technology, 6 (1), 2013, 48-52.

[6]. Njihia BN, Awori KO, Gikenye G. Morphology of the sacral hiatus in an African population - Implications for caudal epidural injections. Annals of African Surgery, 7, 2011, 20-23.

[7]. Smriti, Dev B, Hans D, Raina S. Morphology of sacral hiatus in Dogra region of India. International Journal of Advanced Research, 3(10), 2015, 605-609.

[8]. Aggarwal A, Aggarwal A, Harjeet, Sahni D. Morphometry of sacral hiatus and its clinical relevance in caudal epidural block. Surg Radiol Anat, 31, 2009, 793-800.

[9]. Saikia R, Sarma M. Variations of sacral hiatus in dry human sacra: An anatomical study. J. Evid. Based Med. Healthc. 3(60), 2016, 3238-3242.

[10]. Seema, Singh M, Mahajan A. An anatomical study of variations of sacral hiatus in sacra of North Indian origin and its clinical significance. Int. J. Morphol., 31(1), 2013, 110-4.

[11]. Vasuki AKM, Devi N, Hebzibah DJ, Jamuna M, Sundaram KK, Vimala V. Morphology of sacrum and its variations. IOSR Journal of Dental and Medical Sciences, 15(8), Ver. II, 2016, 129-142.

[12]. Arora S, Dhingra R, Malik VS, Garsa V, Chhabra S. Study of various shapes of sacral hiatus in North Indian population. International Journal of Science and Research, 5(10), 2016, 1328-32.

[13]. Peutrell JM, Mather SJ. Regional anaesthesia in awake children, (London: Oxford, 1996). 